\title{
Association between ambient air pollution exposure and infants small for gestational age in Huangshi, China: a cross-sectional study
}

\author{
Jiayuan Hao ${ }^{1} \cdot$ Faxue Zhang ${ }^{1} \cdot$ Dieyi Chen ${ }^{1} \cdot$ Yanyun Liu $^{2} \cdot$ Lina Liao $^{2} \cdot$ Cui Shen $^{2} \cdot$ Tianyu Liu $^{1} \cdot$ Jingling Liao $^{3}$. \\ Lu Ma ${ }^{1,4}$
}

Received: 4 June 2019 / Accepted: 16 August 2019 / Published online: 6 September 2019

(C) The Author(s) 2019

\begin{abstract}
Small for gestational age (SGA) is defined as intrauterine growth retardation or small sample, referring to the 10th percentile of birth weight lower or two standard deviations less than the average weight at the same gestational age. SGA infants bring great economic and psychological burdens to families and society. The association between exposure to air pollution and SGA in underdeveloped cities with poor air quality remains unclear. Thus, this study is conducted to estimate the effects of maternal exposure to air pollutants on SGA numbers. Birth information was collected from the Huangshi Maternity and Children's Health Hospital from January 1st to December 31st in 2017. Data of pregnancy exposure were accessed using stationary monitors. These data included particulate matter less than or equal to $10 \mu \mathrm{m}$ in aerodynamic diameter $\left(\mathrm{PM}_{10}\right)$, particulate matter less than or equal to $2.5 \mu \mathrm{m}$ in aerodynamic diameter $\left(\mathrm{PM}_{2.5}\right)$, nitrogen dioxide $\left(\mathrm{NO}_{2}\right)$, and sulfur dioxide $\left(\mathrm{SO}_{2}\right)$. Multivariate logistic regression models were performed to estimate the association between ambient air pollution and the risk of SGA during different exposure windows. It was found that a 1 $\mu \mathrm{g} / \mathrm{m}^{3}$ increase in air pollution concentrations during the entire pregnancy was associated with a higher risk of SGA, with an adjusted odds ratio (OR) and 95\% confidence interval (CI) of 1.055 (1.035-1.076), 1.084 (1.053-1.116), 1.000 (0.953-1.049), and 1.051 (0.968-1.141) for $\mathrm{PM}_{10}, \mathrm{PM}_{2.5}, \mathrm{NO}_{2}$, and $\mathrm{SO}_{2}$, respectively. Thus, it is suggested that exposure to air pollution is associated with an increased risk of SGA. The effects of $\mathrm{PM}_{10}$ and $\mathrm{PM}_{2.5}$ were more stable than $\mathrm{NO}_{2}$ and $\mathrm{SO}_{2}$.
\end{abstract}

Keywords Air pollution $\cdot$ Particulate matter $\cdot$ Nitrogen dioxide $\cdot$ Sulfur dioxide $\cdot$ Small for gestational age $\cdot$ Adverse pregnancy outcome

\section{Introduction}

Small for gestational age (SGA) is defined as intrauterine growth retardation or small sample, and it refers to the 10th

\section{Responsible editor: Philippe Garrigues}

Electronic supplementary material The online version of this article (https://doi.org/10.1007/s11356-019-06268-7) contains supplementary material, which is available to authorized users.

Lu Ma

malu@whu.edu.cn

1 Department of Healthcare Management, School of Health Sciences, Wuhan University, Wuhan 430071, China

2 Huangshi Maternity and Children's Health Hospital of Edong Healthcare Group, Huangshi, Hubei Province, China

3 Department of Public Health, Wuhan University of Science and Technology School of Medicine, Wuhan, China

4 Global Health Institute, Wuhan University, Wuhan 430071, China percentile of birth weight lower or two standard deviations less than the average weight at the same gestational age (Ding et al. 2013; Khambalia et al. 2017; Lefebvre and Samoilenko 2017). Similarly, appropriate size for gestational age (AGA) is known as a birth weight within the 10th to 90th percentile of the reference value. SGA is associated with a higher risk of infant morbidity and mortality (Basso et al. 2006). In addition, it can lead to complications in later childhood, such as endocrine and metabolic disturbances (Clayton et al. 2007). However, the risk factors for SGA have not been fully identified, although there are some possible causes, such as teenage motherhood, previous preterm birth, and inadequate prenatal visits (Kildea et al. 2017).

Previous studies have illustrated that exposure to high concentrations of air pollution during pregnancy may decrease uterine blood flow and ultimately slow fetal growth (Browne et al. 2015; Kannan et al. 2006). Maternal exposure to air pollution during pregnancy may be one of the complex set of causes, which increases the risk of impaired fetal 
development and adverse birth outcomes, such as preterm birth and low birth weight (Lamichhane et al. 2015; Li et al. 2017). Whether there is potential association between air pollution and gestational age as a typical factor for fetal growth needs to be addressed.

China has been troubled with air pollution for many years, and the evidence remains inconsistent whether high levels of air pollutants affect the incidence of SGA. Although there are some analyses that have explored the association between air pollution and SGA, most of them have been conducted in developed countries or regions with relatively low air pollution (Michikawa et al. 2017; Rich et al. 2009b; Schlesinger et al. 2006; Wang et al. 2019). To our knowledge, there are no existing studies that have investigated the relationship between air pollution and SGA in central China. Huangshi is an industrial city in central China, and its economic growth has been attributed to mining and metallurgy in recent years (Zhan et al. 2017). Although the concentrations of air pollutants in Huangshi are lower than those in other industrial cities, such as Wuhan (Qian et al. 2016), air pollution exposure in Huangshi is still relatively higher than the air quality guidelines (AQG) issued by the World Health Organization (WHO 2005). For example, compared with the AQG guidelines, the 24-h mean concentrations of particulate matter less than or equal to $10 \mu \mathrm{m}$ in aerodynamic diameter $\left(\mathrm{PM}_{10}\right)$ and particulate matter less than or equal to $2.5 \mu \mathrm{m}$ in aerodynamic diameter $\left(\mathrm{PM}_{2.5}\right)$ exceeded the WHO standard for 327 days and 295 days, respectively, in 2017. There are many prefecture-level industrial cities in central China with low residential mobility, like Huangshi. However, due to subaverage economic and demographic factors, prefecture cities have often been ignored in previous studies. As pregnant women do not have access to advanced medical services during pregnancy as in developed areas, it has been suggested that there might be more severe birth outcomes when pregnant mothers are exposed to eternal environmental pollution.

We chose Huangshi as the study area to investigate whether there are associations between SGA and exposure to air pollution, including $\mathrm{PM}_{10}, \mathrm{PM}_{2.5}$, nitrogen dioxide $\left(\mathrm{NO}_{2}\right)$, and sulfur dioxide $\left(\mathrm{SO}_{2}\right)$. Logistic regression models were constructed in different quartiles to estimate the potential threshold effects. Previous studies have reported that different fetal sexes had different responses towards the environmental simulation in vivo and in vitro, suggesting that infant sex is related to the regulation of birth health (Al-Qaraghouli and Fang 2017; Catalano et al. 2014; Challis et al. 2013; Liu et al. 2018). We also conducted analysis among male infants and female infants during different exposure windows to compare the variation between the different sexes.

\section{Methods}

\section{Study area}

Huangshi $\left(114^{\circ} 31^{\prime}-115^{\circ} 30^{\prime}\right.$ East, $29^{\circ} 30^{\prime}-30^{\circ} 15^{\prime}$ North) is a prefecture-level city in the Hubei province of central China. The city covers an area of $4583 \mathrm{~km}^{2}$ with a population of 2,689,300 people in 2017. With a subtropical monsoon climate, the city's weather is mild and humid. However, as an industrial city, Huangshi has high level of air pollutants according to the WHO guideline values (WHO 2005).

\section{Study population}

Information of mothers and their live births were collected from the Huangshi Maternity and Children's Health Hospital from January 1, 2017, to December 31, 2017. The annual number of births in this hospital accounted for more than $33 \%$ of the city's total delivery. The inclusion criteria included live singleton births after 24 completed weeks and within 42 weeks with complete covariates. In addition, infants whose birth weights were more than the 90th percentile of newborns needed to be excluded. Finally, 4194 singletons were identified (Fig. 1).

The covariates were collected from medical records documented by doctors and nurses after deliveries. The original data was recorded in medical report books and then transformed into electronic form. The collected variables included maternal age, parity, gestational age at birth, date of delivery, delivery mode, infant birth weight, infant sex, and maternal medical conditions during pregnancy including gestational hypertension and gestational diabetes mellitus. The date of conception was calculated using gestational weeks and the date of birth. The gestational age of infants in this study was defined using the adjusted last menstrual period and the delivery date. SGA was determined using a comparison of the weight ranges from the birth weight curve for China (Zhu et al. 2015).

\section{Exposure assessment}

Air pollutant concentrations were obtained from the mirror website of the Environmental Protection Agency (https:// www.aqistudy.cn/historydata/). The 24-h daily concentrations of $\mathrm{PM}_{10}, \mathrm{PM}_{2.5}, \mathrm{NO}_{2}$, and $\mathrm{SO}_{2}$ were collected. The timevarying average concentration approach was utilized to estimate individual exposure.

According to the different exposure windows, a pregnancy period was divided into the first trimester (1-12 weeks), the second trimester (13-27 weeks), and the third trimester (28 weeks to delivery) (Wu et al. 2009). 
Fig. 1 Flow chart of the study population selection

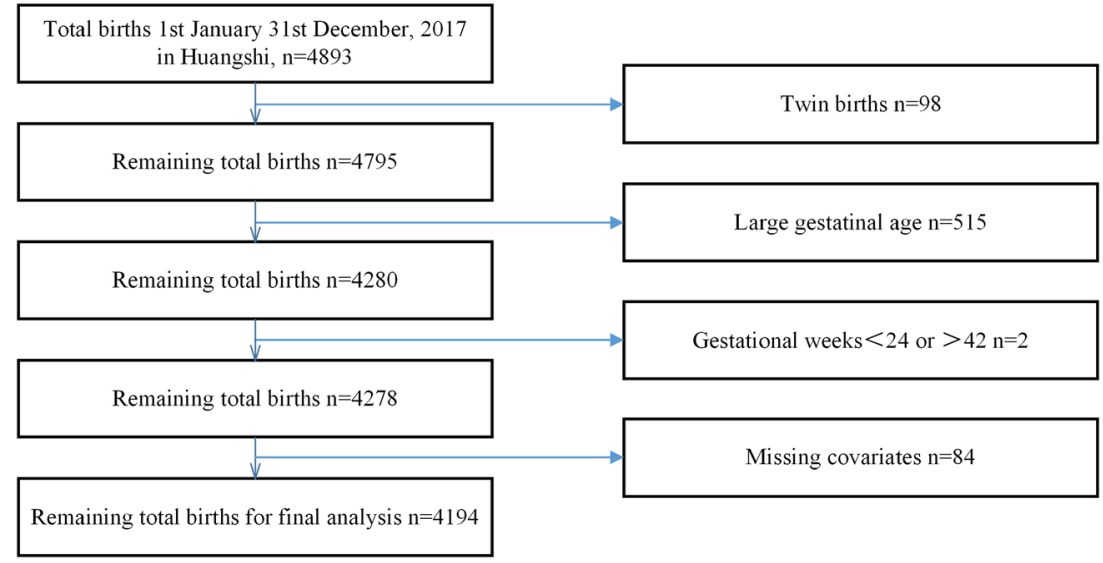

\section{Statistical analysis}

The correlations between each air pollutant were calculated using the Pearson correlation. The chi-squared test for categorical variables and the independent sample $t$ test for continuous variables were conducted for the univariate factor analysis of maternal and infant characteristics. A single-pollutant model and the calculated risk of SGA were conducted separately for each pollutant and pregnancy period.

To further explore the associations between air pollution and SGA, second-stage analyses were performed. Multiple logistic regression models adjusted for covariates were conducted to estimate the specified trimester association between air pollutants and SGA during the entire pregnancy, the first trimester, the second trimester, and the third trimester. All concentrations of pollutants were regarded as continuous variables, and the associations were shown as ORs and 95\% CIs per $1 \mu \mathrm{g} / \mathrm{m}^{3}$ increase in $\mathrm{PM}_{10}, \mathrm{PM}_{2.5}, \mathrm{NO}_{2}$, and $\mathrm{SO}_{2}$.

Stratified analysis of the associations in subgroups for female and male infants was estimated during the different periods. To further explore the effect of air pollutants for their per interquartile range (IQR) increase and to observe the possible threshold effect, the association within subgroups of different quartiles compared with the reference group of the first quartile was assessed. Due to periodic variations in air pollutants, the effects of these seasonal variations on the association of air pollution and SGA were estimated.

Additionally, multi-pollutant models were conducted to explore the potential confounding effects of other pollutants on SGA during each pregnancy period. Due to the high correlation of $\mathrm{PM}_{10}$ and $\mathrm{PM}_{2.5}$, they were not included in one regression.

Statistical tests were two-sided, and a $P$ value $<0.05$ was considered statistically significant. All analyses were conducted using R 3.4.4 software with "tidyverse," "rlist," and "ggplot2" packages.

\section{Results}

The demographic characteristics of the mother-infant pairs are shown in Table 1. A total of 4194 deliveries that met the criteria were collected from the Huangshi Maternity and Children's Health Hospital in 2017. A total of $315(7.5 \%)$ of these deliveries were SGA infants, and 3879 (92.5\%) were AGA infants. The mean gestational age was 38.69 for SGA infants and 38.42 for AGA infants. A total of $84.2 \%$ of the mothers were less than 35 years old at the time of delivery, $2.1 \%$ were diagnosed with gestational hypertension, $3.7 \%$ were accompanied with gestational diabetes mellitus, and for $46.2 \%$ of them, this was their first delivery. Gestational age, maternal age, parity, and gestational diabetes mellitus were not statistically significantly associated with the risk of SGA. The SGA percentile was higher in infants whose mothers were diagnosed with gestational hypertension. In addition, a significantly higher proportion of SGA infants among female newborns were observed $(P<0.001)$.

The average maternal exposures to the four air pollutants during the entire pregnancy are shown in Fig. 2. Women who delivered in summer had a higher exposure level to all the pollutants. The mean concentrations of $\mathrm{PM}_{10}, \mathrm{PM}_{2.5}, \mathrm{NO}_{2}$, and $\mathrm{SO}_{2}$ were $86.8 \mu \mathrm{g} / \mathrm{m}^{3}, 55.3 \mu \mathrm{g} /$ $\mathrm{m}^{3}, 36.5 \mu \mathrm{g} / \mathrm{m}^{3}$, and $17.6 \mu \mathrm{g} / \mathrm{m}^{3}$, respectively. Compared with the AQG released by WHO (annual mean is $20 \mu \mathrm{g} / \mathrm{m}^{3}$ for $\mathrm{PM}_{10}, 10 \mu \mathrm{g} / \mathrm{m}^{3}$ for $\mathrm{PM}_{2.5}$, and $40 \mu \mathrm{g} / \mathrm{m}^{3}$ for $\mathrm{NO}_{2} ; 24-\mathrm{h}$ mean is $20 \mu \mathrm{g} / \mathrm{m}^{3}$ for $\mathrm{SO}_{2}$ ), the maternal exposure concentrations of $\mathrm{PM}_{10}$ and $\mathrm{PM}_{2.5}$ were far above those criteria. The correlations of each of two pollutants were calculated and are shown in Table $\mathrm{S} 1 . \mathrm{PM}_{10}$ and $\mathrm{PM}_{2.5}$ were significantly associated with $\mathrm{SO}_{2}$, and Pearson's correlation coefficients were 0.804 and 0.788 , respectively. $\mathrm{NO}_{2}$ was less strongly correlated with the solid pollutants, and Pearson's correlation coefficients for $\mathrm{PM}_{10}$ and $\mathrm{PM}_{2.5}$ were 0.660 and 0.644 , respectively. 
Table 1 Summary characteristics of participants

\begin{tabular}{llll}
\hline Characteristics & SGA, $n=315$ & AGA, $n=3879$ & t/chi-square $(P)$ \\
\hline Gestational age (weeks, mean (SD) & $38.69 \pm 2.01$ & $38.42 \pm 1.91$ & 0.403 \\
Maternal age, $n(\%)$ & & & \\
$\leq 24$ & $74(23.5)$ & $812(20.9)$ & 0.598 \\
$25-29$ & $104(33.0)$ & $1404(36.2)$ & \\
$30-34$ & $84(26.7)$ & $1054(37.2)$ & \\
$\geq 35$ & $53(16.8)$ & $609(15.7)$ & \\
Parity, $n(\%)$ & & & \\
0 & $158(50.2)$ & $1780(45.9)$ & 0.001 \\
$\geq 1$ & $157(49.8)$ & $2099(54.1)$ & \\
Gestational hypertension, $n(\%)$ & & $74(1.9)$ & 0.400 \\
Yes & $15(4.8)$ & $3805(98.1)$ & \\
No & $300(95.2)$ & $147(3.8)$ & \\
Gestational diabetes mellitus, $n(\%)$ & & $3732(96.2)$ & \\
Yes & $9(2.9)$ & $1874(48.3)$ & 0.601 \\
No & $306(97.1)$ & $2005(51.7)$ & \\
Delivery mode, $n(\%)$ & $157(49.8)$ & $2243(57.8)$ & \\
Vaginal & $158(50.2)$ & & \\
Cesarean & $114(36.2)$ & & \\
Infant sex, $n(\%)$ & $201(63.8)$ & $(42.2)$ & \\
Male & & & \\
Female & & & \\
\hline
\end{tabular}

Chi-square test for categorical variables and independent sample $t$ test for continuous variables
The crude ORs and adjusted ORs (adjusted for maternal age, parity, gestational hypertension, gestational diabetes mellitus, delivery mode, and infant sex) with $95 \%$ CI for each air pollutant and pregnancy period are presented in Table 2. The variation between crude ORs and adjusted ORs was subtle. Exposure to $\mathrm{PM}_{10}$ and $\mathrm{PM}_{2.5}$ was significantly associated with a risk of SGA during the entire pregnancy (aOR [95\% $\mathrm{CI}$ ], 1.055 [1.035-1.076] for $\mathrm{PM}_{10}$ and 1.084 [1.053-1.116] for $\mathrm{PM}_{2.5}$ ), and the adverse effects of $\mathrm{PM}_{2.5}$ were stronger than those of $\mathrm{PM}_{10}$. The effects of $\mathrm{NO}_{2}$ and $\mathrm{SO}_{2}$ were statistically significant during the first and third trimesters. For all of the pollutants, the highest ORs occurred during the third trimester (aOR [95\% CI], 1.018 [1.012-1.024], 1.022 [1.013-1.030], 1.037 [1.019-1.056], and 1.117 [1.082-1.153] for $\mathrm{PM}_{10}$, $\mathrm{PM}_{2.5}, \mathrm{NO}_{2}$, and $\mathrm{SO}_{2}$, respectively). The lowest $\mathrm{ORs}$ appeared during the first trimester, showing as an inverse effect on SGA (aOR [95\% CI], 0.979 [0.971-0.987], 0.976 [0.966-0.986], 0.959 [0.945-0.973], 0.887 [0.857-0.919], respectively). The
Fig. 2 Mean concentrations of maternal exposure to four air pollutants including $\mathrm{PM}_{10}, \mathrm{PM}_{2.5}$, $\mathrm{NO}_{2}$, and $\mathrm{SO}_{2}$ during entire pregnancy

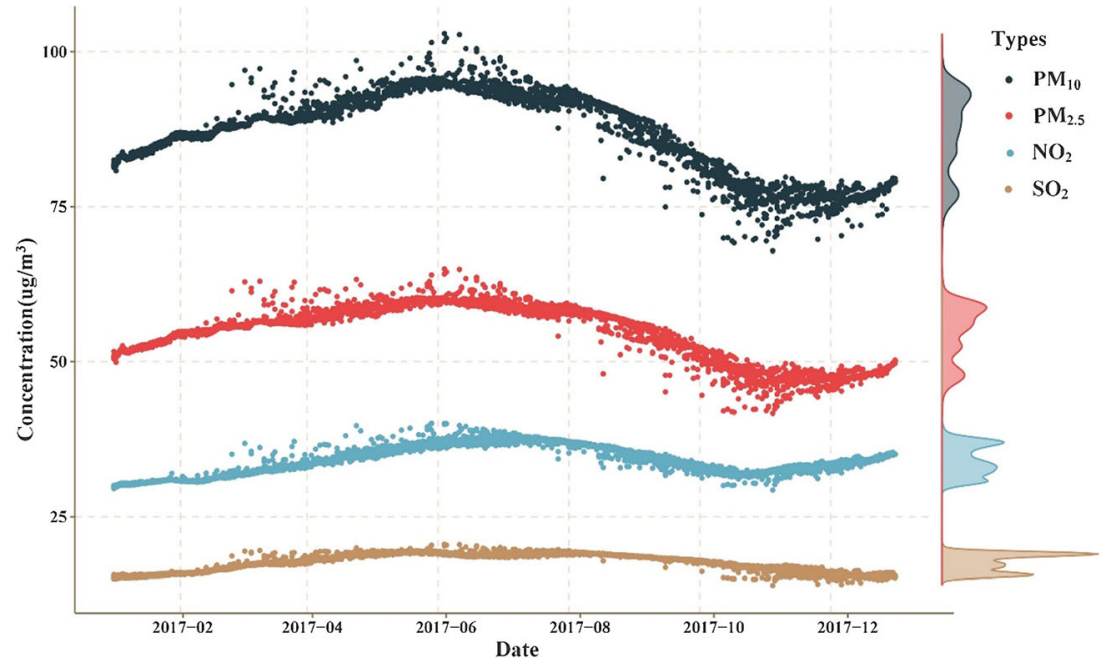


Table 2 Crude and adjusted ORs (95\% CIs) for SGA associated with every $1 \mu \mathrm{g} / \mathrm{m}^{3}$ increase in air pollutants

\begin{tabular}{|c|c|c|c|c|c|c|}
\hline \multirow[t]{2}{*}{ Exposure } & \multicolumn{3}{|l|}{ Crude } & \multicolumn{3}{|c|}{ Adjusted } \\
\hline & $\mathrm{OR}^{\mathrm{a}}$ & $95 \% \mathrm{CI}$ & $P$ & $a \mathrm{OR}^{\mathrm{b}}$ & $95 \% \mathrm{CI}$ & $P$ \\
\hline \multicolumn{7}{|l|}{$\mathrm{PM}_{10}$} \\
\hline Entire pregnancy & 1.692 & $1.384-2.042$ & $<0.001$ & 1.055 & $1.035-1.076$ & $<0.001$ \\
\hline Trimester 1 & 0.817 & $0.753-0.886$ & $<0.001$ & 0.979 & $0.971-0.987$ & $<0.001$ \\
\hline Trimester 2 & 1.138 & $1.062-1.219$ & $<0.001$ & 1.013 & $1.006-1.020$ & $<0.001$ \\
\hline Trimester 3 & 1.184 & $1.116-1.255$ & $<0.001$ & 1.018 & $1.012-1.024$ & $<0.001$ \\
\hline \multicolumn{7}{|l|}{$\mathrm{PM}_{2.5}$} \\
\hline Entire pregnancy & 2.179 & $1.644-2.917$ & $<0.001$ & 1.084 & $1.053-1.116$ & $<0.001$ \\
\hline Trimester 1 & 0.792 & $0.722-0.877$ & $<0.001$ & 0.976 & $0.966-0.986$ & $<0.001$ \\
\hline Trimester 2 & 1.207 & $1.094-1.318$ & $<0.001$ & 1.019 & $1.009-1.028$ & $<0.001$ \\
\hline Trimester 3 & 1.219 & $1.127-1.331$ & $<0.001$ & 1.022 & $1.013-1.030$ & $<0.001$ \\
\hline \multicolumn{7}{|l|}{$\mathrm{NO}_{2}$} \\
\hline Entire pregnancy & 1.020 & $0.638-1.629$ & 0.947 & 1.000 & 0.953-1.049 & 0.913 \\
\hline Trimester 1 & 0.665 & $0.580-0.776$ & $<0.001$ & 0.959 & $0.945-0.973$ & $<0.001$ \\
\hline Trimester 2 & 1.184 & $0.990-1.411$ & 0.065 & 1.016 & $0.998-1.035$ & 0.079 \\
\hline Trimester 3 & 1.424 & 1.195-1.692 & $<0.001$ & 1.037 & 1.019-1.056 & $<0.001$ \\
\hline \multicolumn{7}{|l|}{$\mathrm{SO}_{2}$} \\
\hline Entire pregnancy & 1.629 & $0.722-3.707$ & 0.238 & 1.051 & $0.968-1.141$ & 0.253 \\
\hline Trimester 1 & 0.319 & $0.224-0.449$ & $<0.001$ & 0.887 & 0.857-0.919 & $<0.001$ \\
\hline Trimester 2 & 1.357 & $0.951-1.913$ & 0.091 & 1.029 & $0.993-1.066$ & 0.120 \\
\hline Trimester 3 & 2.814 & $2.061-3.873$ & $<0.001$ & 1.117 & $1.082-1.153$ & $<0.001$ \\
\hline
\end{tabular}

${ }^{\text {a }}$ Crude ORs of air pollutants

${ }^{\mathrm{b}}$ Adjusted ORs for covariates, including maternal age, parity, gestational hypertension, gestational diabetes mellitus, delivery mode, and infant sex effects of air pollutants per IQR increase are presented in Table 3, with the first quartile as a reference. In the case of $\mathrm{PM}_{10}$ and $\mathrm{PM}_{2.5}$, the risk of SGA through the entire pregnancy increased; however, there were no observable remarkable variations among the different quartiles. The effects of $\mathrm{PM}_{10}$ and $\mathrm{PM}_{2.5}$ were obviously strengthened for per IQR rise in pollutants during all the different trimesters. $\mathrm{NO}_{2}$ showed a positive gradient increase in the risk of SGA, with quartiles of exposure in the third trimester ranging from 1.587 to 2.375 . Referring to the first quartile, the effects of $\mathrm{SO}_{2}$ increased with the successive quartiles 2, 3, and 4 during the first and third trimesters.

In the stratified analyses by sex, the effects of air pollution exposure were stronger on male infants (Fig. 3). Exposure to $\mathrm{PM}_{10}$ and $\mathrm{PM}_{2.5}$ was statistically significant during each pregnancy period as pooled infants. The ORs with $95 \%$ CIs of $\mathrm{PM}_{10}$ were 1.067 (95\% CI 1.033-1.103) for males and 1.049 (95\% CI 1.024-1.076) for females during the entire pregnancy. The ORs with $95 \%$ CIs of $\mathrm{PM}_{2.5}$ were 1.100 (95\% CI 1.049-1.154) for males and 1.077 (95\% CI 1.0381.117) for females during the entire pregnancy. The effects of $\mathrm{NO}_{2}$ and $\mathrm{SO}_{2}$ for the two sexes were still statistically significant during the first and third trimesters. The variation between male and female infants during the third trimester was small, and the ORs with 95\% CIs of male and female infants were 1.019 (95\% CI 1.009-1.029) and 1.018 (95\% CI 1.0101.026) for $\mathrm{PM}_{10}, 1.020$ (95\% CI 1.007-1.034) and 1.022 (95\% CI 1.012-1.033) for $\mathrm{PM}_{2.5}, 1.043$ (95\% CI 1.013 1.074 ) and 1.034 (95\% CI 1.011-1.057) for $\mathrm{NO}_{2}$, and 1.116 (95\% CI 1.061-1.174) and 1.119 (95\% CI 1.009-1.029) for $\mathrm{SO}_{2}$.

Two pollutant models were developed to examine the potential confounding effects of other pollutants in our model (Fig. 4). Compared with a single-pollutant model for $\mathrm{PM}_{10}$ and $\mathrm{PM}_{2.5}$ (1.055 1.035-1.076 for $\mathrm{PM}_{10}$ and $1.0841 .053-1.116$ for $\mathrm{PM}_{2.5}$ ), the effects of particulate matter were strengthened when adjusted for $\mathrm{NO}_{2}$ and $\mathrm{SO}_{2}$. The ORs with $95 \%$ CIs of $\mathrm{PM}_{10}$ were 1.119 (95\% CI 1.084-1.155) adjusted for $\mathrm{NO}_{2}$ and 1.153 (95\% CI 1.110-1.197) adjusted for $\mathrm{SO}_{2}$ during the entire pregnancy. Similar to $\mathrm{PM}_{10}$, the ORs with $95 \% \mathrm{CI}$ of $\mathrm{PM}_{2.5}$ were 1.171 (95\% CI 1.120-1.223) adjusted for $\mathrm{NO}_{2}$ and 1.221 (95\% CI 1.158-1.288) adjusted for $\mathrm{SO}_{2}$. However, the effects of $\mathrm{NO}_{2}$ and $\mathrm{SO}_{2}$ were not stable, as some of their effects were strengthened, while some were attenuated due to the collinearity between pollutants. The seasonal analysis showed statistically significant associations between air pollution and SGA in summer and winter (Table S3). 
Table 3 Estimated ORs with 95\% CIs of the risk of SGA for each IQR of air pollutants during each pregnancy period compared with the reference group (lowest quartile)

\begin{tabular}{|c|c|c|c|c|c|c|c|c|c|}
\hline \multirow[t]{2}{*}{ Pollutant } & \multirow[t]{2}{*}{$\mathrm{IQR}^{\mathrm{a}}$} & \multicolumn{2}{|l|}{ Entire pregnancy } & \multicolumn{2}{|l|}{ Trimester 1} & \multicolumn{2}{|l|}{ Trimester 2} & \multicolumn{2}{|l|}{ Trimester 3} \\
\hline & & $\mathrm{OR}^{\mathrm{b}}(95 \% \mathrm{CI})$ & $P$ & OR $(95 \% \mathrm{CI})$ & $P$ & OR $(95 \% \mathrm{CI})$ & $P$ & OR $(95 \% \mathrm{CI})$ & $P$ \\
\hline \multirow[t]{4}{*}{$\mathrm{PM}_{10}$} & Q1 & - & & - & & - & & - & \\
\hline & Q2 & $3.210(2.124-4.852)$ & $<0.001$ & $0.858(0.639-1.152)$ & 0.308 & $1.012(0.710-1.443)$ & 0.946 & $1.375(0.736-2.019)$ & 0.104 \\
\hline & Q3 & $3.241(2.144-4.899)$ & $<0.001$ & $0.521(0.373-0.727)$ & $<0.001$ & $1.224(0.873-1.716)$ & 0.242 & $1.942(1.353-2.786)$ & $<0.001$ \\
\hline & Q4 & $3.038(2.004-4.604)$ & $<0.001$ & $0.475(0.338-0.667)$ & $<0.001$ & $1.590(1.148-2.202)$ & 0.005 & $2.461(1.732-3.498)$ & $<0.001$ \\
\hline \multirow[t]{4}{*}{$\mathrm{PM}_{2.5}$} & Q1 & - & & - & & - & & - & \\
\hline & Q2 & $3.167(2.094-4.789)$ & $<0.001$ & $0.853(0.635-1.147)$ & 0.293 & $1.240(0.868-1.773)$ & 0.237 & $1.563(1.078-2.266)$ & 0.018 \\
\hline & Q3 & $3.159(2.088-4.780)$ & $<0.001$ & $0.570(0.410-0.793)$ & 0.001 & $1.398(0.987-1.980)$ & 0.059 & $1.665(1.154-2.401)$ & 0.006 \\
\hline & Q4 & $3.151(2.083-4.768)$ & $<0.001$ & $0.475\left(0.337 \_0.670\right)$ & $<0.001$ & $1.772(1.267-2.478)$ & 0.001 & $2.385(1.681-3.384)$ & $<0.001$ \\
\hline \multirow[t]{4}{*}{$\mathrm{NO}_{2}$} & Q1 & - & & - & & - & & - & \\
\hline & Q2 & $0.678(0.483-0.951)$ & 0.024 & $0.789(0.587-1.061)$ & 0.116 & $0.666(0.464-0.955)$ & 0.027 & $1.993(1.369-2.903)$ & $<0.001$ \\
\hline & Q3 & $0.786(0.569-1.085)$ & 0.143 & $0.452(0.321-0.637)$ & $<0.001$ & $0.855(0.612-1.194)$ & 0.358 & $2.052(1.412-2.981)$ & $<0.001$ \\
\hline & Q4 & $0.936(0.686-1.277)$ & 0.678 & $0.504(0.363-0.700)$ & $<0.001$ & $1.454(1.072-1.972)$ & 0.016 & $2.375(1.646-3.426)$ & $<0.001$ \\
\hline \multirow[t]{4}{*}{$\mathrm{SO}_{2}$} & Q1 & - & & - & & - & & - & \\
\hline & Q2 & $0.997(0.711-1.397)$ & 0.984 & $0.889(0.669-1.181)$ & 0.418 & $1.277(0.917-1.779)$ & 0.148 & $1.587(1.046-2.410)$ & 0.030 \\
\hline & Q3 & $1.046(0.752-1.455)$ & 0.790 & $0.417(0.297-0.586)$ & $<0.001$ & $1.022(0.723-1.445)$ & 0.902 & $3.138(2.140-4.063)$ & $<0.001$ \\
\hline & Q4 & $1.135(0.822-1.568)$ & 0.442 & $0.339(0.235-0.490)$ & $<0.001$ & $1.309(0.942-1.819)$ & 0.109 & $3.074(2.093-4.515)$ & $<0.001$ \\
\hline
\end{tabular}

${ }^{\text {a }}$ Q1: The first quartile; Q2: The second quartile; Q3: The third quartile; Q4: The fourth quartile

${ }^{\mathrm{b}}$ Adjusted for maternal age, parity, gestational hypertension, gestational diabetes mellitus, delivery mode, and infant sex

\section{Discussion}

This was a cross-sectional study conducted in Huangshi in the eastern Hubei province. Delivery data was collected from the Huangshi Maternity and Children's Health Hospital for the entire year of 2017. In this study, the incidence of SGA was $6.7 \%$, which was lower than the percentile used to define this category (Wang et al. 2019). In this research, exposure to $\mathrm{PM}_{10}$ and $\mathrm{PM}_{2.5}$ was adversely associated with the risk of SGA during all pregnancy periods. The effects of $\mathrm{NO}_{2}$ and
Fig. 3 The estimated ORs of each air pollutant with $95 \%$ CIs during different pregnancy periods stratified by sex adjusted for maternal age, parity, gestational hypertension, gestational diabetes mellitus, delivery mode, and infant sex. EP: entire pregnancy, T1: the first trimester, T2: the second trimester, and T3: the third trimester
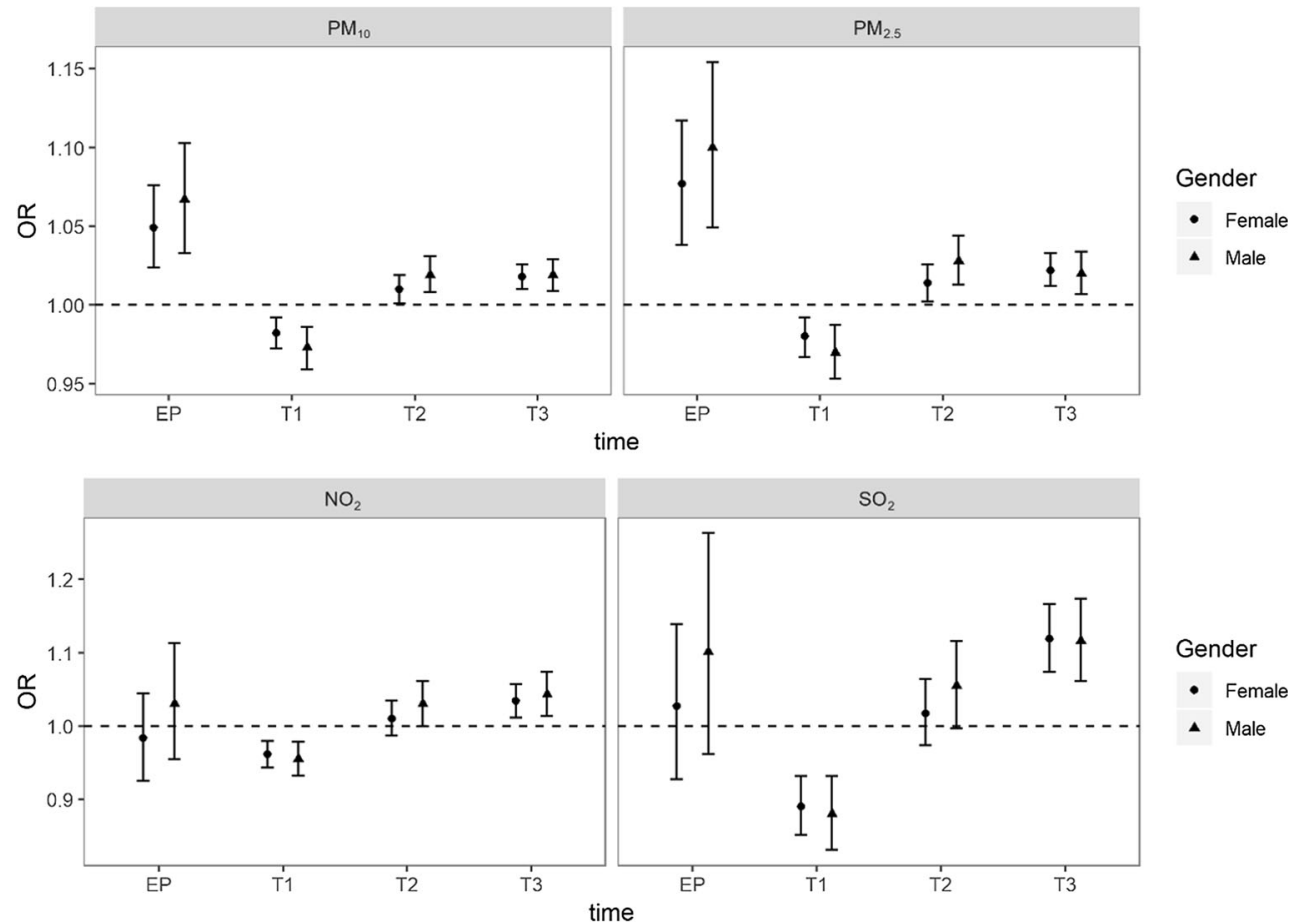
Fig. 4 The estimated ORs for the risk of SGA with $95 \%$ CIs in single-pollutant models and multi-pollutant models adjusted for maternal age, parity, gestational hypertension, gestational diabetes mellitus, delivery mode, and infant sex. EP: entire pregnancy, T1: the first trimester, T2: the second trimester, $\mathrm{T} 3$ : the third trimester

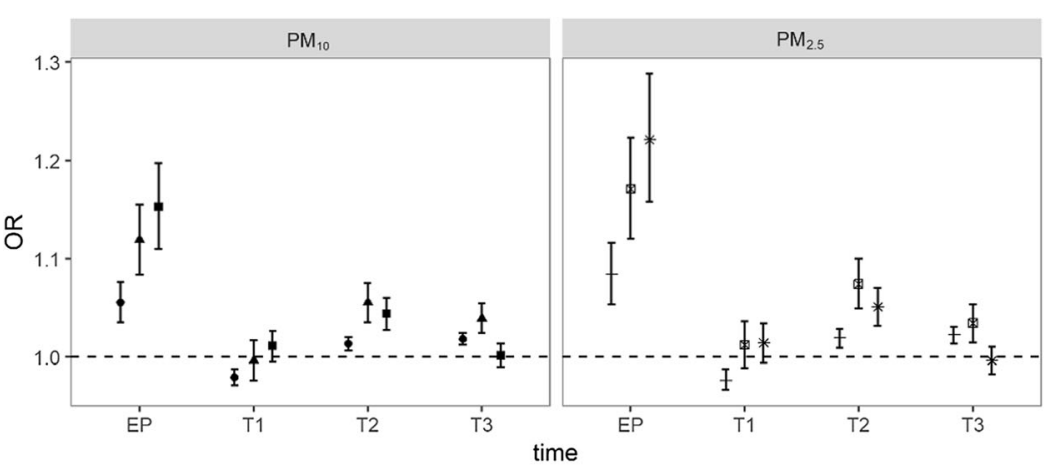

Pollutants
- $\mathrm{PM}_{10}$
- $\mathrm{PM}_{10}$ (with $\mathrm{NO}_{2}$ )
- $\mathrm{PM}_{10}$ (with $\mathrm{SO}_{2}$ )
$+\mathrm{PM}_{2.5}$
ه $\mathrm{PM}_{2.5}$ (with $\mathrm{NO}_{2}$ )
* $\mathrm{PM}_{2.5}$ (with $\mathrm{SO}_{2}$ )

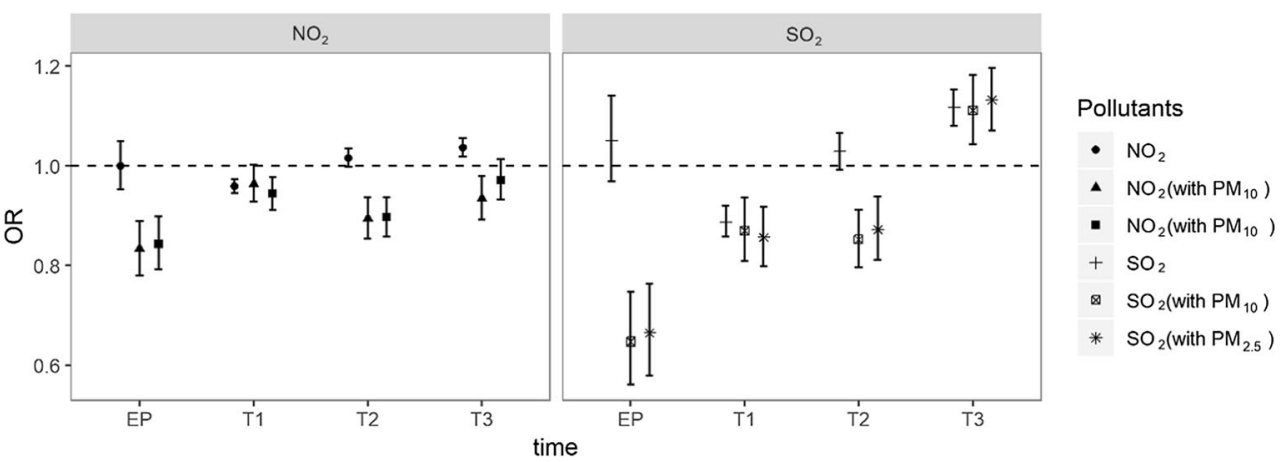

$\mathrm{SO}_{2}$ exposure were less remarkable, but still significant during the first and third trimesters. This is the first population-based cross-sectional study that has investigated the association between SGA and air pollution in central China. The population selected in this study accounted for more than one-third of the infants delivered in Huangshi in the entire year. Therefore, the population was comparatively representative. Compared with other big cities, Huangshi is a prefecture-level city with a lower residential moving rate, indicating that all of the participants had consistent maternal exposure to pollutants.

With the exception of the first trimester, an increased risk of SGA associated with higher levels of $\mathrm{PM}_{10}$ and $\mathrm{PM}_{2.5}$ exposure was observed during the other two trimesters. Despite that many previous studies have examined the effects of $\mathrm{PM}_{10}$ on SGA, the results have remained inconclusive. While studies have provided multiple evidences for an increased risk of SGA with exposure to $\mathrm{PM}_{10}$ in specific trimesters (Ha et al. 2017; Hansen et al. 2007; Le et al. 2012; Mannes et al. 2005), some studies have found a null association between SGA and $\mathrm{PM}_{10}$ (Brauer et al. 2008; Capobussi et al. 2016; Kimberly et al. 2014; Madsen et al. 2010; Wang et al. 2019). Unlike $\mathrm{PM}_{10}$, many previous studies have indicated the adverse effects of $\mathrm{PM}_{2.5}$ on SGA, as found in this study (Mannes et al. 2005; Percy et al. 2019; Ritz et al. 2007; Stieb et al. 2016), but these studies did not reach a consensus on trimester-specific effects. Identified exposure windows for $\mathrm{PM}_{2.5}$ exposure and SGA have been reported in the first trimester (Rich et al. 2009b), the second trimester (Mannes et al. 2005; Wang et al. 2019), the third trimester (Percy et al. 2019;
Rich et al. 2009b), and the entire pregnancy period (Stieb et al. 2016).

In addition to the significant relationships during the first trimester, a positive association was found between $\mathrm{NO}_{2}, \mathrm{SO}_{2}$, and SGA during the third trimester. Some studies have found a positive association between $\mathrm{NO}_{2}$ exposure and SGA in specific trimesters (Ballester et al. 2010; Stieb et al. 2016; Wang et al. 2019); however, some studies have also reported no evidence of adverse impacts from $\mathrm{NO}_{2}$ on SGA (Mannes et al. 2005; Rich et al. 2009a; Ritz et al. 2007; Taylor et al. 2016). Previous studies regarding the association between $\mathrm{SO}_{2}$ and SGA have remained inconclusive, with several studies having reported no association, while others have found a weak association (Ha et al. 2017; Le et al. 2012; Rich et al. 2009a). In summary, previous studies have not observed a stable and positive association between $\mathrm{NO}_{2}, \mathrm{SO}_{2}$, and SGA.

The discrepancies among this study and previous studies may be attributed to many factors. First, as mentioned, most studies regarding the association between air pollution and SGA have been conducted in developed areas, and the lifestyles of the study populations, such as nutrition, cooking methods, and medical care, which could vary from those of women in Huangshi. Second, many studies adopted more accurate methods based on residential address to estimate the individual exposure, while this study used the mean concentrations collected from monitory station, suggesting a variability of exposure assessment (Percy et al. 2019; Wang et al. 2019). Third, spatial heterogeneity could result in distinct composition of air pollutants, which means that even 
pollutants with the same concentrations could result in very different exposures (Bell et al. 2010).

In this study, it was found that exposure to ambient air pollution decreased the risk of SGA during the first trimester, which seems not biologically plausible and inconsistent with previous studies. Most studies have found adverse effects from ambient air pollutants. One potential explanation for this discrepancy is that embryos that were easily injured were aborted or resulted in stillbirths in the early maternal stage of air pollutant exposure. However, in this study, only singleton live births were considered; thus, the population that was selected in this study was partially biased (Percy et al. 2019).

During the third trimester, the risk of SGA grew greater than during other periods as the concentration of air pollutants increased. The third trimester is a very important period for fetal growth because the most rapid fetal development occurs in this period (Grantz et al. 2018). Hence, the fetus may be more vulnerable than during other periods. The biological mechanism of the adverse impacts from air pollution on newborns remains unclear. It is assumed that air pollutants could alter fetal growth by causing oxidative stress or inflammation, reducing placental exchange of nutrients and gases, negatively affecting placental growth, fostering endocrine disruption, or causing negative maternal health effects (Kannan et al. 2006). Another hypothesis is that air pollution can affect the mitochondria. For instance, exposure to $\mathrm{NO}_{2}$ causes damage to mitochondrial DNA, which is related to infant birth weight (Clemente et al. 2016). Prenatal $\mathrm{PM}_{10}$ exposure has been associated with placental mitochondrial alterations, which may both reflect and intensify oxidative stress production (Janssen et al. 2012).

In this time-stratified analysis, it was found that exposure to air pollution in summer and winter was associated with SGA morbidity. The increased risk of SGA in summer may be the result of high-temperature exposure. Heat stress could cause damage to the antioxidant defense system and result in a larger secretion amount of oxytocin (Forgati et al. 2017), which could have a negative impact on maternal health and fetal growth. The association in winter could be explained by a deficiency in vitamin D. Vitamin D has been found to be negatively correlated to SGA risk (Wang et al. 2018), and the level of vitamin D in winter in China is much lower than that in summer (Yang and Zhang 2013).

In the subgroup analysis, it was found that the effects of environmental exposure to air pollution could be modified by infant sex, which has been mentioned in many previous studies (Lee et al. 2014; Liu et al. 2018; Taylor et al. 2016; Wainstock et al. 2014). Lee et al. (2014) suggested that prenatal exposure to bisphenol A played a different role in birth weights between male infants and female infants in a multicenter birth cohort study from Korea (Lee et al. 2014). A study in Shanghai, China, found that maternal exposure to household air pollution could contribute to adverse birth outcomes in boys but not in girls (Liu et al. 2018). However, a population-based study in the UK showed that moderate prenatal cadmium exposure was associated with lower birth weights in girls but not in boys (Taylor et al. 2016). In addition, one retrospective cohort study reported that exposure to prenatal maternal stress was a risk factor only in female fetuses (Wainstock et al. 2014). These findings suggest that sexual differences may alter the effects of the external environment, and variations between sexes should be noticed. Some studies have attempted to provide biologically plausible explanations for these variations. Male fetuses were assumed to have greater potential susceptibility to a pro-inflammatory environment during pregnancy. In vitro studies have shown that when infected, cells from pregnancies with a male fetus were observed to have an increase in production of proinflammatory cytokines, including tumor necrosis factor and prostaglandin synthase, and had a smaller quantity of antiinflammatory cytokines and prostaglandin dehydrogenase compared with female infants (Al-Qaraghouli and Fang 2017; Challis et al. 2013; Liu et al. 2018).

The quartile assessment showed that the risk of SGA under exposure to $\mathrm{PM}_{10}$ and $\mathrm{PM}_{2.5}$ was not distinct during the entire pregnancy. However, the trimester-specific analysis showed that the effects of $\mathrm{PM}_{10}$ and $\mathrm{PM}_{2.5}$ became stronger with increasing concentrations, suggesting that the risk for SGA could increase without a threshold effect of pollutants as the concentration of $\mathrm{PM}_{10}$ and $\mathrm{PM}_{2.5}$ increased. The associations between $\mathrm{NO}_{2}, \mathrm{SO}_{2}$, and SGA were not as stable as particulate matter, but an OR increase in SGA still was observed per IQR increase during the third trimester. Previous studies have not reached a consistent conclusion on how air pollutants with different quartiles affect SGA, as they have reported no significantly positive associations or even a decreased risk of SGA for higher levels of $\mathrm{PM}_{10}$ and $\mathrm{NO}_{2}$ (Eh et al. 2012; Hansen et al. 2007; Wu et al. 2018). In summary, whether higher concentrations of air pollutants will lead to increased risk of SGA requires further research.

Several limitations should be considered when interpreting this research. The accurate address of each pregnant woman was not acquired. Therefore, the mean concentration of each air quality monitoring station in Huangshi was used to replace individual exposure. The lack of an accurate maternal exposure model may lead to some misclassifications due to the fact that air pollutant concentration levels are not homogenous across different locations. In this cross-sectional study, only pregnancy data for the year of 2017 was collected, which is a research period restriction. In further studies, a larger cohort that covers several continuous years needs to be collected to observe the effect of air pollution on SGA based on a retrospective study. Due to the hospital location in central Huangshi, the population recruited was primarily from the urban city; thus, the condition of rural areas could not be presented in this research. 
In this study, although SGA was found to have a $2 \%$ to $10 \%$ increased risk when exposed to air pollution during the third trimester, considering the high concentration of air pollutants in Huangshi, exposure to ambient air pollution is still a severe risk factor for fetal growth restriction. Therefore, these findings are significant enough to encourage the government to take actions to reduce air pollutant emissions to improve the health condition of pregnant women and their infants. It is worthwhile to continue air quality improvements for the prevention of SGA infants and to reduce the costs associated with SGA infants later in life.

\section{Conclusion}

In this cross-sectional study, it was found that maternal exposure to air pollution was significantly associated with SGA. Overall, the adverse effects of $\mathrm{PM}_{10}$ and $\mathrm{PM}_{2.5}$ were stronger than gaseous pollutants, including $\mathrm{NO}_{2}$ and $\mathrm{SO}_{2}$. In addition, the third trimester was found to be the most vulnerable period for fetuses when exposed to air pollution. These findings can provide a basis for air quality management policies and the promotion of neonatal health. More studies in other prefecture cities with high levels of air pollutants should be conducted, which conform to this study in the future.

Funding information This research was funded by the Health Commission of Hubei Province (grant number WJ2017M008).

\section{Compliance with ethical standards}

Conflict of interest The authors declare that they have no conflict of interest.

Open Access This article is distributed under the terms of the Creative Commons Attribution 4.0 International License (http:// creativecommons.org/licenses/by/4.0/), which permits unrestricted use, distribution, and reproduction in any medium, provided you give appropriate credit to the original author(s) and the source, provide a link to the Creative Commons license, and indicate if changes were made.

\section{References}

Al-Qaraghouli M, Fang YMV (2017) Effect of fetal sex on maternal and obstetric outcomes. Frontiers in Pediatrics 5:144. https://doi.org/10. 3389/fped.2017.00144

Ballester F, Estarlich M, Iñiguez C, Llop S, Ramón R, Esplugues A, Lacasaña M, Rebagliato M (2010) Air pollution exposure during pregnancy and reduced birth size: a prospective birth cohort study in Valencia, Spain. Environmental Health: a Global Access Science Source 9:6-6. https://doi.org/10.1186/1476-069X-9-6

Basso O, Wilcox AJ, Weinberg (2006) Birth weight and mortality: causality or confounding? American Journal of Epidemiology 164: 303-311. https://doi.org/10.1093/aje/kwj237
Bell ML, Kathleen B, Keita E, Gent JF, Hyung Joo L, Petros K, Leaderer BP (2010) Prenatal exposure to fine particulate matter and birth weight: variations by particulate constituents and sources. J Epidemiology 21:884-891. https://doi.org/10.1097/ede. 0b013e3181f2f405

Brauer M, Lencar C, Tamburic L, Koehoorn M, Demers P, Karr C (2008) A cohort study of traffic-related air pollution impacts on birth outcomes. Environmental health perspectives 116:680-686. https://doi. org/10.1289/ehp.10952

Browne VA, Julian CG, Lillian TJ, Darleen CR, Enrique V, Moore LG (2015) Uterine artery blood flow, fetal hypoxia and fetal growth. J Philosophical Transactions of the Royal Society B Biological Sciences 370:20140068. https://doi.org/10.1098/rstb.2014.0068

Capobussi M, Tettamanti R, Marcolin L, Piovesan L, Bronzin S, Gattoni ME, Polloni I, Sabatino G, Tersalvi CA, Auxilia F, Castaldi S (2016) Air pollution impact on pregnancy outcomes in Como, Italy. Journal of Occupational and Environmental 58:47-52. https://doi.org/10. 1097/JOM.0000000000000630

Catalano R, Karasek D, Gemmill A, Falconi A, Goodman J, Magganas A, Hartig T (2014) Very low birthweight: dysregulated gestation versus evolutionary adaptation. Social Science \& Medicine 108: 237-242. https://doi.org/10.1016/j.socscimed.2014.01.050

Challis J, Newnham J, Petraglia F, Yeganegi M, Bocking A (2013) Fetal sex and preterm birth. J Placenta 34:95-99. https://doi.org/10.1016/ j.placenta.2012.11.007

Clayton PE, Cianfarani S, Czernichow P, Johannsson G, Rapaport R, Rogol A (2007) Management of the child born small for gestational age through to adulthood: a consensus statement of the International Societies of Pediatric Endocrinology and the Growth Hormone Research Society. The Journal of Clinical Endocrinology \& Metabolism 92:804-810. https://doi.org/10.1210/jc.2006-2017

Clemente DBP, Casas M, Vilahur N, Begiristain H, Bustamante M, Carsin AE, Fernández MF, Fierens F, Gyselaers W, Iñiguez C, Janssen BG, Lefebvre W, Llop S, Olea N, Pedersen M, Pieters N, Santa Marina L, Souto A, Tardón A, Vanpoucke C, Vrijheid M, Sunyer J, Nawrot TS (2016) Prenatal ambient air pollution, placental mitochondrial DNA content, and birth weight in the INMA (Spain) and ENVIRONAGE (Belgium) birth cohorts. Environmental Health Perspectives 124:659-665. https://doi.org/10.1289/ehp.1408981

Ding G, Tian Y, Zhang Y, Pang Y, Zhang J, Zhang J (2013) Application of a global reference for fetal-weight and birthweight percentiles in predicting infant mortality. BJOG 120:1613-1621. https://doi.org/ 10.1111/1471-0528.12381

Eh VDH, Pierik FH, De KY, Willemsen SP, Hofman A, van Ratingen SW, Zandveld PY, Mackenbach JP, Steegers EA, Miedema HMJEHP (2012) Air pollution exposure during pregnancy, ultrasound measures of fetal growth, and adverse birth outcomes: a prospective cohort study. Environ Health Perspect 120:150-156. https://doi.org/10.1289/ehp.1003316

Forgati M, Kandalski PK, Herrerias T, Zaleski T, Machado C, Souza MRDP, Donatti L, Forgati M, Kandalski PK, Herrerias T et al (2017) Effects of heat stress on the renal and branchial carbohydrate metabolism and antioxidant system of Antarctic fish. J Comp Physiol B 187:1-18. https://doi.org/10.1007/s00360-017-1088-3

Grantz KL, Hediger ML, Liu D, Buck Louis GM (2018) Fetal growth standards: the NICHD fetal growth study approach in context with INTERGROWTH-21st and the World Health Organization Multicentre Growth Reference Study. Am J Obstet Gynecol 218: S0002937817324419. https://doi.org/10.1016/j.ajog.2017.11.593

Ha S, Zhu Y, Liu D, Sherman S, Mendola P (2017) Ambient temperature and air quality in relation to small for gestational age and term low birthweight. Environmental research 155:394-400. https://doi.org/ 10.1016/j.envres.2017.02.021

Hansen C, Neller A, Williams G, Simpson R (2007) Low levels of ambient air pollution during pregnancy and fetal growth among term 
neonates in Brisbane, Australia. Environmental Research 103:383389. https://doi.org/10.1016/j.envres.2006.06.010

Janssen BG, Munters E, Pieters N, Smeets K, Cox B, Cuypers A, Fierens F, Penders J, Vangronsveld J, Gyselaers W, Nawrot TS (2012) Placental mitochondrial DNA content and particulate air pollution during in utero life. Environmental Health Perspectives 120:13461352. https://doi.org/10.1289/ehp.1104458

Kannan S, Misra DP, Dvonch JT, Krishnakumar A (2006) Exposures to airborne particulate matter and adverse perinatal outcomes: a biologically plausible mechanistic framework for exploring potential effect modification by nutrition. Environmental Health Perspectives 114:1636-1642. https://doi.org/10.1289/ehp.9081

Khambalia AZ, Algert CS, Bowen JR, Collie RJ, Roberts CL (2017) Long-term outcomes for large for gestational age infants born at term. J Paediatr Child Health 53:876-881. https://doi.org/10.1111/ jpc. 13593

Kildea SV, Gao Y, Rolfe M, Boyle J, Tracy S, Barclay LM (2017) Risk factors for preterm, low birthweight and small for gestational age births among Aboriginal women from remote communities in Northern Australia. Women and Birth 30:398-405. https://doi.org/ 10.1016/j.wombi.2017.03.003

Kimberly H, Roseanne MN, Philip B, Colin S, Raymond AJ (2014) Air pollution exposure and adverse pregnancy outcomes in a large UK birth cohort: use of a novel spatio-temporal modelling technique. Scand J Work Environ Health 40:518-530. https://doi.org/10. 5271/sjweh.3423

Lamichhane DK, Leem JH, Lee JY, Kim HC (2015) A meta-analysis of exposure to particulate matter and adverse birth outcomes. Environmental Health \& Toxicology 30:e2015011. https://doi.org/ 10.5620/eht.e2015011

Le HQ, Batterman SA, Wirth JJ, Wahl RL, Hoggatt KJ, Sadeghnejad A, Hultin ML, Depa M (2012) Air pollutant exposure and preterm and term small-for-gestational-age births in Detroit, Michigan: longterm trends and associations. Environment International 44:7-17. https://doi.org/10.1016/j.envint.2012.01.003

Lee B-E, Park H, Hong Y-C, Ha M, Kim Y, Chang N, Kim B-N, Kim YJ, Yu S-D, Ha E-H (2014) Prenatal bisphenol A and birth outcomes: MOCEH (Mothers and Children's Environmental Health) study. International Journal of Hygiene and Environmental Health 217: 328-334. https://doi.org/10.1016/j.ijheh.2013.07.005

Lefebvre G, Samoilenko M (2017) Correction to: On the use of the outcome variable "small for gestational age" when gestational age is a potential mediator: a maternal asthma perspective. BMC Medical Research Methodology 17:165. https://oi.org/10.1186/ s12874-018-0477-y

Li X, Huang S, Jiao A, Yang X, Yun J, Wang Y, Xue X, Chu Y, Liu F, Liu $Y$ (2017) Association between ambient fine particulate matter and preterm birth or term low birth weight: an updated systematic review and meta-analysis is. Environmental Pollution 227:596-605. https://doi.org/10.1016/j.envpol.2017.03.055

Liu W, Huang C, Cai J, Wang X, Zou Z, Sun C (2018) Household environmental exposures during gestation and birth outcomes: a cross-sectional study in Shanghai, China. Science of The Total Environment 615:1110-1118. https://doi.org/10.1016/j.scitotenv. 2017.10.015

Madsen C, Gehring U, Erik Walker S, Brunekreef B, Stigum H, Næss Ø, Nafstad P (2010) Ambient air pollution exposure, residential mobility and term birth weight in Oslo, Norway. Environmental Research 110:363-371. https://doi.org/10.1016/j.envres.2010.02.005

Mannes T, Jalaludin B, Morgan G, Lincoln D, Sheppeard V, Corbett S (2005) Impact of ambient air pollution on birth weight in Sydney, Australia. Occupational and Environmental Medicine 62:524-530. https://doi.org/10.1136/oem.2004.014282

Michikawa T, Morokuma S, Fukushima K, Kato K, Nitta H, Yamazaki S (2017) Maternal exposure to air pollutants during the first trimester and foetal growth in Japanese term infants. Environmental Pollution 230:387-393. https://doi.org/10.1016/j.envpol.2017.06.069

Percy Z, DeFranco E, Xu F, Hall ES, Haynes EN, Jones D, Muglia LJ, Chen A (2019) Trimester specific PM2.5 exposure and fetal growth in Ohio, 2007-2010. Environmental Research 171:111-118. https:// doi.org/10.1016/j.envres.2019.01.031

Qian Z, Liang S, Yang S, Trevathan E, Huang Z, Yang R, Wang J, Hu K, Zhang Y, Vaughn M, Shen L, Liu W, Li P, Ward P, Yang L, Zhang W, Chen W, Dong G, Zheng T, Xu S, Zhang B (2016) Ambient air pollution and preterm birth: a prospective birth cohort study in Wuhan, China. Int J Hyg Environ Health 219:195-203. https://doi. org/10.1016/j.ijheh.2015.11.003

Rich DQ, Demissie K, S-E L, Kamat L, Wartenberg D, Rhoads GG (2009a) Ambient air pollutant concentrations during pregnancy and the risk of fetal growth restriction. J Journal of Epidemiology, Health C 63:488-496. https://doi.org/10.1136/jech.2008.082792

Rich DQ, Demissie K, Lu SE, Kamat L, Wartenberg D, Rhoads GG (2009b) Ambient air pollutant concentrations during pregnancy and the risk of fetal growth restriction. Journal of epidemiology and community health 63:488-496. https://doi.org/10.1136/jech. 2008.082792

Ritz B, Wilhelm M, Hoggatt KJ, Ghosh JKC (2007) Ambient air pollution and preterm birth in the environment and pregnancy outcomes study at the University of California, Los Angeles. American Journal of Epidemiology 166:1045-1052. https://doi.org/10.1093/ aje/kwm181

Schlesinger RB, Kunzli N, Hidy GM, Gotschi T, Jerrett M (2006) The health relevance of ambient particulate matter characteristics: coherence of toxicological and epidemiological inferences. Inhalation Toxicology 18:95-125. https://doi.org/10.1080/ 08958370500306016

Stieb DM, Chen L, Hystad P, Beckerman BS, Jerrett M, Tjepkema M, Crouse DL, Omariba DW, Peters PA, van Donkelaar A, Martin RV, Burnett RT, Liu S, Smith-Doiron M, Dugandzic RM (2016) A national study of the association between traffic-related air pollution and adverse pregnancy outcomes in Canada, 1999-2008. Environmental Research 148:513-526. https://doi.org/10.1016/j. envres.2016.04.025

Taylor CM, Golding J, Emond AM (2016) Moderate prenatal cadmium exposure and adverse birth outcomes: a role for sex-specific differences? Paediatric and perinatal epidemiology 30:603-611. https:// doi.org/10.1111/ppe.12318

Wainstock T, Shoham-Vardi I, Glasser S, Anteby E, Lerner-Gev LJ (2014) Fetal sex modifies effects of prenatal stress exposure and adverse birth outcomes. Stress 18:49-56. https://doi.org/10.3109/ 10253890.2014 .974153

Wang H, Xiao Y, Zhang L, Gao Q (2018) Maternal early pregnancy vitamin $\mathrm{D}$ status in relation to low birth weight and small-forgestational-age offspring. The Journal of Steroid Biochemistry and Molecular Biology 175:146-150. https://doi.org/10.1016/j.jsbmb. 2017.09.010

Wang Q, Benmarhnia T, Li C, Knibbs LD, Bao J, Ren M, Zhang H, Wang S, Zhang Y, Zhao Q, Huang C (2019) Seasonal analyses of the association between prenatal ambient air pollution exposure and birth weight for gestational age in Guangzhou, China. Science of The Total Environment 649:526-534. https://doi.org/10.1016/j. scitotenv.2018.08.303

WHO (2005) Air quality guidelines - global update 2005. Accessed 25 April 2019

Wu J, Ren C, Delfino RJ, Chung J, Wilhelm M, Ritz B (2009) Association between local traffic-generated air pollution and preeclampsia and preterm delivery in the south coast air basin of California. Environmental health perspectives 117:1773-1779. https://doi.org/10.1289/ehp.0800334

Wu H, Jiang B, Geng X, Zhu P, Liu Z, Cui L, Yang L (2018) Exposure to fine particulate matter during pregnancy and risk of term low birth 
weight in Jinan, China, 2014-2016. International Journal of Hygiene and Environmental Health 221:183-190. https://doi.org/ 10.1016/j.ijheh.2017.10.013

Yang L, Zhang W (2013) Seasonal vitamin D and bone metabolism in women of reproductive age in urban Beijing. Asia Pacific Journal of Clinical Nutrition 26:427-433. https://doi.org/10.6133/apjen. 042016.01

Zhan C, Zhang J, Zheng J, Yao R, Wang P, Liu H, Xiao W, Liu X, Cao J (2017) Characterization of carbonaceous fractions in PM2.5 and PM10 over a typical industrial city in central China.
Environmental Science and Pollution Research. https://doi.org/10. 1007/s11356-017-9970-9

Zhu L, Zhang R, Zhang S, Shi W, Chen C (2015) Chinese neonatal birth weight curve for different gestational age. Zhonghua er ke za zhi. Chinese Journal of Pediatrics 53(2):97-103

Publisher's note Springer Nature remains neutral with regard to jurisdictional claims in published maps and institutional affiliations. 